\title{
Некоторые весеннецветущие виды растений флоры Дальнего Востока и Сибири в биоколлекциях ботанического сада ВИЛАР
}

\section{Some spring flowering species of plants of the Far East and Siberia flora in bio botanical garden VILAR}

\author{
Кытина М. А., Минязева Ю. М. \\ Kytina M. A., Minyazeva Y. M. \\ Всероссийский институт лекарственных и ароматических растений, г. Москва, Россия. E-mail: bot.gard.vilar@yandex.ru
}

All-Russian Institute of Medicinal and Aromatic Plants, Moscow, Russia

Peфepam. По многолетним данным представлены результаты изучения особенностей сезонного ритма развития некоторых весеннецветущих травянистых видов растений флоры Дальнего Востока и Сибири в условиях Ботанического сада ВИЛАР. Исследуемые виды в условиях Ботанического сада проявляют устойчивость и долголетие популяций.

Ключевые слова. Биоколлекции, весеннецветущие растения, флора Сибири, флора Дальнего Востока.

Summary. According to long-term data, the results of studying the seasonal rhythm peculiarities of the development of some spring-flowering herbaceous plant species of the Far East and Siberia flora in the conditions of the Botanical garden of VILAR are presented. The studied species show stability and longevity of populations in the conditions of the Botanical garden.

Key words: Biocollections, spring-flowering plants, flora of Siberia, flora of the Far East.

Весеннецветущие растения начинают вегетационный период (сезон вегетации) и создают яркий неповторимый акцент. Весенняя растительность особенно привлекательна, что способствует повышению уровня антропогенного влияния. Огромный урон флоре наносит массовый сбор красиво цветущих ранних весенних растений для букетов. Многие раннецветущие растения попадают в категорию редких и исчезающих видов, так как интенсивно используются как декоративные и лекарственные.

Цель исследований - изучение травянистых раннецветущих растений в условиях Ботанического сада ВИЛАР.

Изучение сезонного ритма развития видов флоры Дальнего Востока и Сибири проводилось в условиях Ботанического сада ВИЛАР на биоколлекции региона флоры Дальнего Востока, площадью 5,3 га.

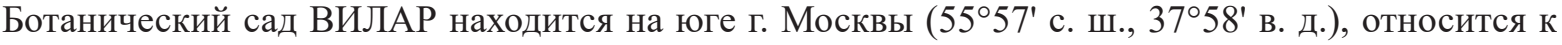
подзоне смешанных лесов. Среднегодовая сумма осадков- 575 мм. Почвы тяжелосуглинистые, дерново-подзолистые. Климат умеренно континентальный, характеризуется хорошо выраженными переходными сезонами. Средняя температура самого тёплого месяца (июля) $+18,2{ }^{\circ} \mathrm{C}$, средняя температура самого холодного месяца (января) $-11^{\circ} \mathrm{C}$. Устойчивый снежный покров образуется обычно в конце ноября; к концу зимы его высота достигает в среднем 30-45 см. Переход температуры через $0{ }^{\circ} \mathrm{C}$ к более высоким значениям весной происходит в апреле, к более низким - осенью, в ноябре; продолжительность этого период - 160-230 дней. Из-за большой изменчивости атмосферной циркуляции погода часто изменчива (Агроклиматический справочник, 1967).

Объектами исследований являлись 16 видов весеннецветущих растений флоры Дальнего Востока и Сибири, из 9 семейств, 10 родов: Aristolochiaceae Juss.: Asarum L. - A. sieboldii Miq.; Asteraceae Dumort.: Petasites Hill. - P. amplus Kitam.; Berberidaceae Juss.: Plagiorhegma Maxim. - P. dubia Max- 
im. (Jeffersonia dubia (Maxim.) Benth. et Hook. f. ex Baker et Moore); Epimedium L. - E. koreanum Nakai; E. macrosepalum Stearn; Boraginaceae Juss.: Brunnera Stev. - B. sibirica Stev.; B. macrophylla (Adams) I. M. Johnst.; Chloranthaceae R. Br. ex Lindl.: Chloranthus Sw. - Ch. japonicus Siebold; Convallariaceae L.: Smilacina Desf. - S. hirta Maxim.; Liliaceae Juss.: Fritillaria L. - F. ussuriensis Maxim. ; Papaveraceae Juss.: Hylomecon Maxim. - H. vernalis Maxim.; Paeoniaceae Rudolphi: Paeonia L. - P. anomala L.; P. lactiflora Pall.; P.obovata Maxim; Saxifragaceae Juss.: Bergenia Moench - B. crassifolia (L.) Fritsch; B.pacifica Kom. Названия таксонов представлены в соответствии со сводкой С. К. Черепанова (1995).

Из представленных видов большая часть - 15 , являются корневищными многолетниками, 1 луковичный многолетник (Fritillaria ussuriensis).

Исходный семенной и посадочный материал был получен из отечественных ботанических садов, ряд видов привезён живыми растениями из экспедиционных поездок, из природных мест обитания.

Все находящиеся в изучении растения представляют интерес как раннецветущие декоративные виды. Лекарственным действием обладают: Asarum sieboldii, Bergenia crassifolia, B. pacifica, Brunnera macrophylla, Chloranthus japonicus, Paeonia anomala, P. lactiflora, P.obovata, Epimedium koreanum, E. macrosepalum, Plagiorhegma dubia, Petasites amplus, Smilacina hirta, Fritillaria ussuriensis, Plagiorhegma dubia (Шретер, 1975; Недолужко, Денисов, 2001; Растительные ресурсы СССР, 1984-1996; Красная книга Амурской области, 2009)

Большинство изученных видов в пределах России произрастают на Дальнем Востоке, часть являются представителями сибирской флоры. Epimedium macrosepalum в пределах России встречается только в юго-восточных районах Приморского края и является узкоареальным эндемиком юго-восточных отрогов Сихотэ-Алиня; реликтовый вид Epimedium koreanum встречается в северной части Хасанского района Приморского края. Plagiorhegma dubia на территории России встречается в Хабаровском и Приморском краях; реликтовый вид. Ареал Bergenia pacifica расположен на территории Приморского края, в южной части Хабаровского края, по хребту Сихотэ-Алинь вплоть до долины р. Амур; эндемик хребта Сихотэ-Алинь. Bergenia crassifolia имеет ареал, охватывающий горные системы Алтая, Тывы, Саян, Кузнецкий Алатау, а также Прибайкалье. Brunnera sibirica - встречается в районах с влажным климатом на Алтае, Кузнецком Алатау, в Западном и Восточном Саяне (в пределах Красноярского края) и в северо-восточной части Республики Тыва; алтае-западно-саянский эндемик, реликт третичных широколиственных лесов. B. macrophylla встречается на юге Приморского края (заносное). Smilacina hirta произрастает в Приморском и Хабаровском крае, Амурской области и Еврейской AO. Fritillaria ussuriensis произрастает в Приморском крае, за исключением высокогорных, таежных и лесостепных районов, и в единственном пункте на юге Хабаровского края. Paeonia lactiflora в России растет в Забайкальском крае, Амурской области, Еврейской АО, в Хабаровском (в основном на юго-востоке) и Приморском краях. P. obovata в России произрастает в Амурской, Сахалинской областях, Еврейской АО, в Хабаровском (в южной части) и Приморском краях. P. anomala сибирский вид, ареал частично заходит на северо-восток европейской части страны, Урал; произрастает в Казахстане, Средней Азии. В Сибири распространён на востоке до Прибайкалья и западной части бассейна р. Лены; крайними восточными точками ареала являются местонахождения в бассейне р. Джида на отрогах хр. Хамар-Дабан. Chloranthus japonicus - в России вид встречается в Приморском, Хабаровском крае, Амурской, Сахалинской области и Еврейской $\mathrm{AO}$, на Курильских о-вах. Hylomecon vernalis встречается в Приморском крае и на юго-востоке Амурской области Asarum sieboldii встречается на юге Приморского края. Petasites amplus в пределах России встречается на Дальнем Востоке, главным образом на Сахалине, Курильских о-вах, в Хабаровском крае, где известен из единственного местонахождения (Николаевский р-н) (Сосудистые растения ..., 1987; Флора Сибири, 1987-2003).

Численность природных популяций 13 видов (81\%) сокращается и может быть стабилизирована специальными мерами охраны. Chloranthus japonicas, Hylomecon vernalis, Petasites amplus, Plagiorhegma dubia, Fritillaria ussuriensis, Paeonia lactiflora, P.obovata, P. anomala, Bergenia pacifica, B. crassifolia, Epimedium koreanum и E. macrosepalum - виды, которые подвергаются активному антропогенному воздействию (сбор на букеты, заготовка лекарственного сырья). Chloranthus japonicas, Hylomecon vernalis, Petasites amplus, Plagiorhegma dubia, Fritillaria ussuriensis, Paeonia lactiflora, P.obova- 
ta, Epimedium koreanum и E. macrosepalum страдают из-за хозяйственного освоения территории и нарушения естественных местообитаний, рекреационной нагрузки. Сокращение природных популяций Epimedium koreanum и E. macrosepalum происходит также из-за низкой и неустойчивой репродуктивной способности видов, разобщённости и малочисленности популяций. Лимитирующими факторами для Brunnera sibirica являются особенности биологии вида, предпочитающего для своего развития условия относительно влажного климата, а также разрушение природных мест обитания.

Все изучаемые виды, кроме Asarum sieboldii, Smilacina hirta, Brunnera macrophylla, охраняются на местном уровне и внесены в региональные Красные книги редких и нуждающихся в охране видов растений российского Дальнего Востока и Сибири, часть из них охраняется на государственном уровне и включены в Красную книгу Российской Федерации (КК РФ). Epimedium koreanum - вид, находящийся под угрозой исчезновения, внесён в КК РФ, категория охраны - 1 и в КК Приморского края. E. macrosepalum - редкий вид, внесён в КК РФ, категория охраны - 3 и в КК Приморского края. Fritillaria ussuriensis - редкий вид, на северо-восточной границе ареала, внесен в КК РФ, категория охраны -3, а также в КК Приморского края и КК Хабаровского края. Paeonia lactiflora - вид, сокращающийся в численности, внесен в КК РФ (2008), категория охраны - 2; включен в КК Читинской и Амурской областей, Еврейской АО, Забайкальского края, Хабаровского края, Приморского края. P. obovata - редкий вид, внесён в КК РФ, категория редкости - 3, а также в КК Амурской области, Еврейской автономной области, Приморского края, Сахалинской области, Хабаровского края. P. anomala - вид, сокращающийся в численности, включён в КК Республики Бурятия. Забайкальского края, Иркутской области; Кемеровской области, Омской области, Республики Саха (Якутия). Bergenia pacifica - уязвимый вид, внесён в КК Приморского края и Хабаровского края. B. crassifolia - внесён в КК Республики Саха (Якутия). Brunnera sibirica - вид внесён в КК Алтайского края, Красноярского края, Томской области, Республики Тыва. Plagiorhegma dubia - редкий реликтовый вид, с ограниченным ареалом на территории российского Дальнего Востока, внесён в КК Хабаровского края. Petasites amplus - вид с неопределённым статусом, состояние которого нуждается в мониторинге, включён в КК Хабаровского края. Chloranthus japonicus, Hylomecon vernalis -редкие виды, включены в КК Амурской области (Редкие и исчезающие ..., 1980; Красная книга РФ, 2008; ИАС «ООПТ РФ», 2019).

Для понимания успешности интродукции указанных видов проанализирована многолетняя динамика их роста и развития в условиях Ботанического сада, по результатам наблюдений с 2009 по 2018 гг. Сезонный ритм развития растений изучали в соответствии с методикой фенологических наблюдений в ботанических садах (Александрова, 1975). Изучение успешности интродукции проводилось в соответствии с методикой исследований при интродукции лекарственных растений (Майсурадзе, 1984).

Фенологические даты, полученные в результате многолетних наблюдений (10 лет), подвергались математической обработке. Для вычисления статистических показателей фенологические даты переводились в условные числа непрерывного ряда с помощью вспомогательной таблицы. Для дат наступления фенологических явлений высчитывались арифметическое среднее и стандартное отклонение, характеризующее границы интервала типичности; исходя из того, что многолетние фенологические процессы близки к нормальному распределению (Зайцев, 1978; Доспехов, 1985).

Сезонное развитие видов характеризуется постоянной очерёдностью наступления фенологических фаз развития, под которыми, в свою очередь, понимаются внешние проявления сезонных изменений растений. Проведённые исследования показывают, что ритм сезонного развития дальневосточных и сибирских видов зависит от погодных условий. В ходе многолетних фенологических исследований в Ботаническом саду были установлены календарные даты основных фаз развития, определены средние значения сроков и продолжительности цветения (табл.).

Все изученные виды по типу отрастания относятся к группе растений с ранневесенним отрастанием. Начало отрастания у представленной группы растений приходится, в среднем по многолетним данным, на период с 13 апреля по 01 мая. Первыми отрастают виды, температурный минимум начала роста у которых близок к $0^{\circ} \mathrm{C}$, а вегетация начинается при малой сумме положительных температур, сразу после схода снежного покрова; это виды с эфемероидным ритмом развития (Fritillaria ussuriensis, Hylomecon vernalis), а также виды с зимнезелёными листьями (Epimedium koreanum, E. macrosepalum, Bergenia crassifolia, B.pacifica). 
Средние даты наступления основных фенологических фаз дальневосточных и сибирских видов растений в условиях Ботанического сада ВИЛАР (2009-2018 гг.)

\begin{tabular}{|l|c|c|c|c|c|c|c|}
\hline \multirow{2}{*}{\multicolumn{1}{|c|}{ Вид }} & \multirow{7}{*}{ Год } & \multicolumn{7}{c|}{ Средние даты $(\bar{x})$} \\
\cline { 3 - 8 } & поступления & Бутонизация & $\mathrm{s}$ & Цветение & $\mathrm{s}$ & Плодоношение & $\mathrm{s}$ \\
\hline Asarum sieboldii & 1978 & $20.04 \pm 2,6$ & 8,2 & $09.05 \pm 3,5$ & 11,1 & $29.05 \pm 3,7$ & 11,8 \\
\hline Petasites amplus & 1959 & $13.04 \pm 3,1$ & 9,9 & $19.04 \pm 2,6$ & 8,1 & $01.05 \pm 2,7$ & 8,5 \\
\hline Smilacina hirta & 1975 & $03.05 \pm 0,6$ & 1,9 & $18.05 \pm 2,0$ & 6,4 & $20.06 \pm 3,5$ & 11,1 \\
\hline Plagiorhegma dubia & 1960 & $21.04 \pm 1,8$ & 5,8 & $02.05 \pm 1.5$ & 4,6 & $19.05 \pm 2,4$ & 7,6 \\
\hline Hylomecon vernalis & 1978 & $29.04 \pm 1,7$ & 5,5 & $10.05 \pm 2,0$ & 6,3 & $03.06 \pm 2,4$ & 7,7 \\
\hline Fritillaria ussuriensis & 1968 & $01.05 \pm 2,4$ & 7,5 & $15.05 \pm 3,0$ & 9,5 & $09.06 \pm 4,7$ & 14,9 \\
\hline Brunnera sibirica & 1991 & $28.04 \pm 1,8$ & 5,5 & $20.05 \pm 4,6$ & 14,4 & $20.06 \pm 5,0$ & 15,8 \\
\hline Brunnera macrophylla & 2001 & $01.05 \pm 1,7$ & 5,5 & $12.05 \pm 1,9$ & 6,0 & $02.06 \pm 4,1$ & 13,1 \\
\hline Bergenia crassifolia & 1980 & $26.04 \pm 1,9$ & 5,9 & $18.05 \pm 4,2$ & 13,3 & $19.06 \pm 7,3$ & 23,1 \\
\hline Bergenia pacifica & 1970 & $26.04 \pm 2,1$ & 6,6 & $10.05 \pm 2,3$ & 7,3 & $04.06 \pm 2,5$ & 7,8 \\
\hline Chloranthus japonicus & 1960 & $01.05 \pm 1,4$ & 4,3 & $12.05 \pm 2,7$ & 8,4 & $09.06 \pm 6,8$ & 21,6 \\
\hline Epimedium macrosepalum & 2006 & $03.05 \pm 1,6$ & 5,1 & $11.05 \pm 1,9$ & 6,0 & $26.05 \pm 3,1$ & 9,9 \\
\hline Epimedium koreanum & 1978 & $01.05 \pm 2,1$ & 6,5 & $15.05 \pm 2,4$ & 7,6 & $15.06 \pm 3,3$ & 10,6 \\
\hline Paeonia obovata & 1960 & $13.05 \pm 3,5$ & 11,1 & $18.05 \pm 4,1$ & 13,1 & $18.06 \pm 4,2$ & 13,3 \\
\hline Paeonia lactiflora & 1972 & $15.05 \pm 2,8$ & 8,7 & $30.05 \pm 2,5$ & 8,0 & $20.06 \pm 2,5$ & 7,9 \\
\hline Paeonia anomala & 1995 & $08.05 \pm 3,2$ & 10,1 & $22.05 \pm 2,9$ & 9,3 & $08.06 \pm 2,9$ & 9,2 \\
\hline
\end{tabular}

Примечание: ${ }^{\bar{x}}$ - среднее арифметическое $; \bar{x} \pm S_{X}$ - абсолютная ошибка средней арифметической $\mathrm{s}$ - стандартное отклонение от среднего арифметического.

Анализ успешности интродукции видов проводился с учётом ритмологических признаков - peгулярности цветения и плодоношения, а также продолжительности жизни интродукционных популяций в условиях Ботанического сада. Цветение - основной критерий состояния вида и показатель соответствия условий внешней среды его требованиям. Начало вегетации и цветения растений зависят от комплекса условий: времени схода снежного покрова, оттаивания почвы, устойчивости погодных условий в начале вегетации, интенсивности нарастания температурного режима. Все изученные виды имеют весенне-раннелетний ритм цветения, и в средней полосе России цветут со II декады апреля (19.04) до II (20.06) декады июня и наиболее полно используют благоприятные весенние факторы - достаточные освещенность и увлажненность. Отмечено, что большая часть изучаемых раннецветущих видов - 9 (56 \%) цветёт во II декаде мая. Раньше всех зацветают: Petasites amplus - во II-й декаде апреля, Asarum sieboldii, P. dubia, Hylomecon vernalis, Bergenia pacifica - во І-й декаде мая; позже зацветают Paeonia lactiflora u Paeonia anomala. По продолжительности цветения выделены группы растений, цветущие 10-19 дней, 20-29 дней, 30 и более дней. Более продолжительным цветением отличаются Smilacina hirta, Brunnera sibirica, Chloranthus japonicus, Epimedium koreanum цветущие 30-35 дней, Asarum sieboldii, Hylomecon vernalis, Fritillaria ussuriensis, Bergenia pacifica, B. crassifolia, Paeonia lactiflora, Paeonia obovate имеют среднюю продолжительность цветения - 20-27 дней. К наиболее быстроцветущим - 13-19 дней, отнесены следующие виды Petasites amplus, Plagiorhegma dubia, Brunnera macrophylla, Epimedium macrosepalum, Paeonia anomala. Общий период цветения изучаемой группы растений в коллекции составил 63 дня. Условия во время зацветания могут влиять на продолжительность этой фазы.

По длительности вегетации из изученной группы выделены коротковегетирующие виды - Fritillaria ussuriensis и Hylomecon vernalis, заканчивающие вегетацию в июле, период вегетации составляет, в среднем $85 \pm 4,1$ и $68 \pm 3,1$ дней соответственно. У Hylomecon vernalis вегетация полновозрастных плодоносящих особей в июле заканчивается, а молодых вегетативных продолжается до II декады августа - I-II декады сентября. Все остальные виды являются длительновегетирующими, их активная 
вегетация начинается в апреле и продолжается, в зависимости от условий года, до октября - ноября; и составляет от $110 \pm 5,5$ (Paeonia obovata) до $162 \pm 3,9$ дней - Plagiorhegma dubia, этот вид сохраняет листья до поздней осени. Зимнезелёные виды - Bergenia crassifolia, B.pacifica, Epimedium koreanum Nakai; E. macrosepalum, заканчивают вегетацию в конце вегетационного периода, с появлением устойчивого снежного покрова, период вегетации этих видов составляет от 199 до 214 дней.

В качестве показателя успешности интродукции была принята, помимо цветения, также способность растений к плодоношению. Достигают фазы плодоношения в условиях Ботанического сада 11 видов (69\%): Asarum sieboldii, P. dubia, Hylomecon vernalis, F. ussuriensis, Bergenia pacifica, B. crassifolia, Paeonia anomala, P. lactiflora, P. obovata., Chloranthus japonicus. Эти виды размножаются семенами и вегетативно, но преобладает вегетативное размножение. Chloranthus japonicus семена образует, но они часто невыполненные; Fritillaria ussuriensis даёт зрелые семена редко, только в самые благоприятные по погодным условиям годы; Smilacina hirta семена образует ежегодно, но они малочисленные. У Brunnera macrophylla u B. sibirica в результате биологических особенностей видов наблюдается низкая семенная продуктивность и высокая активность вегетативного размножения; в коллекции возобновляются вегетативным способом. У B. sibirica первая генерация листьев засыхает в июле, вторая генерация сохраняется до октября-ноября. Epimedium koreanum, E. macrosepalum, Petasites amplus размножаются вегетативно.

Проявляют склонность к естественному самовозобновлению в условиях сада 13 видов (81\%): Epimedium koreanum, E. macrosepalum, Bergenia pacifica, B. crassifolia, Plagiorhegma dubia, Smilacina hirta, Asarum sieboldii, Brunnera macrophylla, B. sibirica, Petasites amplus, Hylomecon vernalis, Fritillaria ussuriensis.

По длительности нахождения интродукционных популяций в составе коллекции Ботанического сада ВИЛАР все изученные виды относятся к долголетним и находятся в коллекции более 10 лет. Наиболее долголетними, поддерживающимися в коллекции свыше 35 лет, являются популяции Bergenia crassifolia - 38 лет, Hylomecon vernalis, Epimedium koreanum, Asarum sieboldii - 40 лет, Smilacina hirta - 43 года, Paeonia lactiflora - 46 лет, Bergenia pacifica - 48 лет, Fritillaria ussuriensis - 50 лет, Plagiorhegma dubia, Chloranthus japonicus, Paeonia obovata - 58 лет и Petasites amplus - 59 лет. Виды Epimedium macrosepalum, Brunnera macrophylla, Paeonia anomala, Brunnera sibirica - в составе коллекции 12 лет, 17лет, 23 года и 27 лет соответственно.

Анализ фенологических наблюдений показал, что исследуемые виды различаются по ритму развития. Показатель начала вегетации подвержен годовой изменчивости. Это связано, в первую очередь, с погодно-климатическими условиями, сроками и скоростью таяния снега, а также зависит от биологических особенностей видов. Средние значения сроков начала вегетации позволяют сказать, что начало отрастания весеннецветущих растений наблюдается во II декаде апреля. Начало вегетации не оказывает существенного влияния на время начала цветения.

Наблюдения показали, что изучаемые виды в условиях Ботанического сада ВИЛАР активно вегетируют, ежегодно продуцируют цветоносы и обильно цветут. За вегетационный период все изучаемые виды успевают пройти цикл развития до плодоношения. Достигают фазы плодоношения 11 видов (69 \%), проявляют способность к самовозобновлению в условиях Ботанического сада 13 (81 \%). Все изученные виды, кроме Fritillaria ussuriensis, Hylomecon vernalis, относятся к длительновегетирующими растениями с периодом вегетации 110 и более дней.

Сроки наступления фенологических фаз могут варьировать в разные годы в зависимости от погодных условий. Отсутствие или нерегулярность плодоношения объясняется климатическими условиями и биологическими особенностями видов.

\section{ЛИТЕРАТУРА}

Александрова М. С. Методика фенологических наблюдений в ботанических садах СССР. - М.: Изд-во АН CCCP, 1975. - 27 c.

Агроклиматический справочник по Московской области / Упр. гидрометеорол. службы Центр. областей; авт. разделов О. Б. Зворыкина, Т. И. Бурцева и др. -Москва: Моск. рабочий, 1967. - 135 с. 
Доспехов Б. А. Планирование полевого опыта и статистическая обработка его данных: учеб. пособие для высш. с.-х. учеб. заведений. - М.: Колос, 1972. - 207 с.

Зайцев Г. Н. Фенология травянистых многолетников. - М.: Наука, 1978. - 149 с.

ИАС «ООПТ РФ» [эллектронный pecypc]. URL: http://www.oopt.aari.ru/ (дата обращения: март, 2019).

Майсурадзе, Н.И. Методика исследований при интродукции лекарственных растений» обзорная информация. $/$ Н.И. Майсурадзе [и др.] - М.: ЦБНТИ Минмедбиопрома, 1984. - 32 с.

Красная книга Амурской области: Редкие и находящиеся под угрозой исчезновения виды животных, растений и грибов: официальное издание. - Благовещенск: Издательство БГПУ, 2009. - 446 с.

Красная книга Российской Федерации (Растения и грибы). / Гл. ред. Ю. П. Трутнев и др., сост. Р. В. Камелин и др. - Москва, Товарищество научных изданий КМК, 2008. -855 с.

Недолужко В. А., Денисов Н. И. Флора сосудистых растений острова Русский (залив Петра Великого в Японском море). - Владивосток: Дальнаука, 2001. - 98 с.

Pacmuтельные pecypcы СССР: Цветковые растения, их химический состав, использование // Справочник цветковых растений СССР. - Ленинград: Наука, 1984-1996. - Т. 1-9.

Редкие и исчезающие растения Сибири. - Новосибирск: Наука, 1980 - С. 30.

Сосудистые растения советского Дальнего Востока / под ред. С. С. Харкевича. - Л.: Наука, 1987. - Т. 2. $446 \mathrm{c}$.

Флора Сибири. - Новосибирск: Наука. Сиб. Отд-е, 1987-2003. - Т. 1-14.

Черепанов С. К. Сосудистые растения России и сопредельных государств (в пределах бывшего СССР). -СПб.: Мир и семья, 1995. - 992 с.

Шретер А. И. Лекарственная флора Советского Дальнего Востока. - М.: «Медицина», 1975. - 328 с. 